\title{
Hydrothermal processing of pine wood: effect of process variables on bio-oil quality and yield
}

\author{
Mariusz Wądrzyk ${ }^{1,2^{*}}$, Magdalena Berdel ${ }^{1,3}$, Rafat Janus ${ }^{1,2}$, and Derk Willem Frederik \\ Brilman $^{3}$ \\ ${ }^{1}$ AGH University of Science and Technology, Faculty of Energy and Fuels, al. Mickiewicza 30, 30- \\ 059 Krakow, Poland \\ ${ }^{2}$ AGH University of Science and Technology, AGH Centre of Energy, ul. Czarnowiejska 36, 30-054 \\ Krakow, Poland \\ ${ }^{3}$ University of Twente, Faculty of Science and Technology, PO Box 217, 7500 AE Enschede, The \\ Netherlands
}

\begin{abstract}
Hydrothermal liquefaction processes (HTL) comprise complex chemical and physical transformations of biomass under the conditions of high temperature and pressure, commonly near- or supercritical water. During this processes, the components of biomass undergo various complicated chemical reactions strongly influenced by process variables. In this study, lignocellulosic biomass (pine wood) has been converted via liquefaction in subcritical water to bio-oil, water-soluble organics, gas and solid products. The process parameters (i.e. temperature and time processing) affecting the bio-oil yields and composition were comparatively studied. The chemical composition of resulting bio-oils was analyzed by means of mid-infrared spectroscopy, gel permeation chromatography, gas chromatography coupled to mass spectrometry and elemental analysis. The maximum bio-oil yield ( $38.35 \mathrm{wt} . \%$ ) was obtained at $350{ }^{\circ} \mathrm{C}$ for $10 \mathrm{~min}$. The $\mathrm{HHV}$ of the obtained resultant bio-oils varied in the range of $24-28 \mathrm{MJ} \cdot \mathrm{kg}^{-1}$. Bio-oils from HTL of pine wood are complex mixtures of aromatic and cyclic compounds with numerous hydroxyl and carboxyl functional groups. The experiments exhibited that the increase in the temperature results in a deeper decomposition of biomass manifested by the higher yield of bio-oil and its gradual deoxygenation. In fact, the obtained oil products are promising, valuable intermediates, which may act as a source of many valueadded chemicals.
\end{abstract}

\section{Introduction}

Biomass is a renewable source of energy which is widely available and needs to be valorized. In particular, woody biomass is considered as one of the most prospective and significant resource. According to [1] total biomass accounted for two-thirds of the gross inland energy consumption of renewables in the EU-28 in 2015. More specifically, in many EU countries, wood was the most important single source of energy among all renewables. For instance,

\footnotetext{
* Corresponding author: wadrzyk@agh.edu.pl
} 
wood comprised over $75 \%$ of renewable energy consumed in Estonia, Latvia, Finland and Poland [1]. In the last few decades, the possibility of conversion of lignocellulosic biomass was the research object of many scientists worldwide [2-4]. One of the main drawbacks of woody biomass utilization is the high content of moisture and low energy density of this type of raw material [5]. Therefore, conventional thermochemical processes like pyrolysis and carbonization, which require the moisture content level below a few percentages, are not cost-effective. However, the conversion of highly-moisture biomass in near-critical water opens the way to avoid the aforementioned issues and enables to receive the bioproducts without energy-consuming drying step. The hydrothermal liquefaction (HTL) is a process of deep chemical transformation of biomass occurring in an aqueous medium at elevated temperatures and pressures Typically, the hydrothermal liquefaction is carried out at the temperatures of $250-374{ }^{\circ} \mathrm{C}$ under the pressures of 4-22 MPa [5]. In such conditions, water exhibits certain unique properties which result in favourable liquids production from organic matter. For example, near the critical point of water (i.e. $374{ }^{\circ} \mathrm{C}$ and $22.1 \mathrm{MPa}$ ), its dissociation constant rises drastically, causing water to act as acid or base catalyst for numerous reactions and empowering the chemical conversion of almost each type of organic compounds via hydrolysis and ionic reactions [6-8]. At supercritical conditions radical reactions start to dominate over ionic mechanism leading to higher gas fraction yields. In majority of available research, the temperature range of $250-350{ }^{\circ} \mathrm{C}$ covers the optimal conditions for bio-oil production. Thus the minimum and maximum values of the mentioned range was selected for presented investigation. The recent scientific literature provides several valuable review papers concerning hydrothermal liquefaction of different kinds of biomass $[3,5,6,8-10]$. More specifically, there are also available research papers devoted to the conversion of different kinds of woody biomass processed under hydrothermal conditions, e.g. pine wood [11, 12], beech wood [13] or birch wood [14]. It is worth mentioning that although HTL is an extremely perspective process, scaling up and implementation of it into industry practice is a difficult and complicated challenge. This study revealed that pine wood as one of the most abundant renewable resources could be efficiently converted to valuable bioproducts. The impact of the key process conditions (i.e. temperature and processing time) on the yield and composition of the ultimate bio-oil, as a targeted fraction was investigated.

\section{Materials and methods}

\subsection{Feedstock}

Pine wood was used as a feedstock for hydrothermal processing tests. The raw material was purchased from Rettenmaier \& Söhne $\mathrm{GmbH}$ in Germany. The pine wood particle size was $<0,5 \mathrm{~mm}$. The feedstock was preliminary dried in an laboratory oven for $24 \mathrm{~h}$ at $105^{\circ} \mathrm{C}$. Table 1 presents the feedstock composition.

Table 1. Ultimate and proximate analysis of the feedstock [15].

\begin{tabular}{cccc}
\hline Chemical analysis & wt.\%, dry & Ultimate analysis & wt.\%, daf \\
\hline Cellulose & 35 & $\mathrm{C}$ & 46.58 \\
Hemicellulose & 29 & $\mathrm{H}$ & 6.34 \\
Lignin & 28 & O (by difference) & 46.98 \\
Alkali metals & & $\mathrm{N}$ & 0.04 \\
K & 0.0034 & $\mathrm{~S}$ & 0.06 \\
Mg & 0.0134 & $\mathrm{H} / \mathrm{C}$ & $1.63[-]$ \\
Ca & 0.0768 & $\mathrm{O} / \mathrm{C}$ & $0.76[-]$ \\
Total ash & 0.26 & $\mathrm{HHV}$ & $18.57\left[\mathrm{MJ}^{-1} \mathrm{~kg}^{-1}\right]$ \\
\hline
\end{tabular}




\subsection{Experimental setup}

The complete scheme of the setup used for batch autoclave HTL experiments is displayed in Fig. 1.

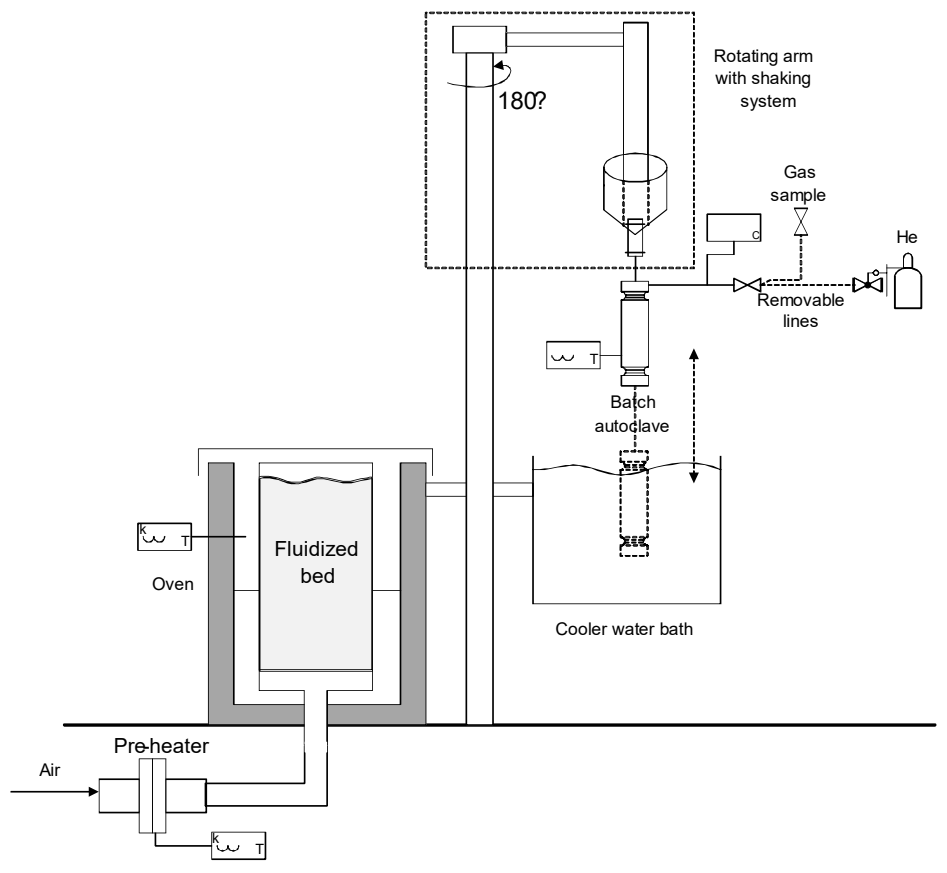

Fig. 1. Scheme of the setup used for pine wood hydrothermal processing experiments.

The autoclave used, made of an Incoloy alloy, has a volume of $45 \mathrm{~cm}^{3}$. Prior to the experiment, a gas-tightness test was carried out for three times by filling the reactor with nitrogen (50 bar). Typically, approximately $18 \mathrm{~g}$ of wood slurry was placed in the reactor in a nitrogen atmosphere under the initial pressure of 5 bar. The concentration of the dry biomass in the slurry was kept constant at $10 \mathrm{wt} . \%$ (in distilled water). The set processing temperature inside the reactor (i.e. 250 and $350^{\circ} \mathrm{C}$ ) was reached by its immersion in a fluidized sand bed heated by an electric furnace. Depending on the set process temperature, the preheating time varied from 7 to 10 minutes. The reaction was carried out under an autogenous pressure. After finishing the reaction, the autoclave was submerged into cooling water bath (kept at ambient temperature). The reaction time was defined as a period between the moment when the set reaction temperature was reached and the commence of cooling. After the contents of the autoclave achieved ambient temperature, the gas pressure was recorded, and sample was taken for analysis. Then, the autoclave was opened and the products were transferred into the collector.

\subsection{Product separation}

In order to isolate the bio-oil from as-received reaction mixture, the typical procedure of the extraction with dichloromethane (DCM; Sigma Aldrich 99.9\%) was employed, according to the method reported elsewhere [16]. Ultimately, four following products were isolated from the reaction mixture: (i) bio-oil; (ii) water phase containing dissolved polar organics; (iii) volatile phase; and (iv) solid residue. Herein, the bio-oil was defined as the mixture of DCM-soluble organics. The yield of gaseous (non-condensable) products evolved during 
HTL process was computed according to the ideal gas law, based on the temperature and pressure inside the reactor. The mass balance closure for the performed tests varied in the range of 80-100 wt.\%. The product yields for the chosen reaction parameters discussed in the next sections were calculated as the average values of two repetitions. The relative standard deviations for discussed points were below $15 \%$.

\subsection{Product analysis}

Elemental analysis $(\mathrm{C}, \mathrm{H}, \mathrm{N})$ of the studied feedstock and final products was carried out using Thermo Scientific Flash 2000 apparatus. The oxygen content was determined by difference. Each run was repeated twice. Higher heating values (HHV) of pine wood and ultimate bio-oils were calculated according to Boie's formula.

The composition of the prepared bio-oils was investigated by means of mid-infrared Fourier-transform spectroscopy. The spectra were collected on a FTIR Tensor 27 (Bruker) spectrometer. In order to enable a comparative analysis of the bio-oils, the spectra were normalized using Kubelka-Munk approach.

The determination of the molecular mass distribution of the bio-oils was carried out using an Agilent 1200 series HPLC system equipped with three GPC PLgel MIXED-E columns (diameter of $3 \mu \mathrm{m}$ ) coupled in outlet-to-inlet cascade. The system was equipped with the refractive index detector (RID) and the variable wavelength detector (VWD).

The composition of volatile products of pine wood-derived bio-oils was analyzed using gas chromatography coupled to mass spectrometry (GC-MS). The analyses were performed on GC-MS Agilent type GC 7890A equipped with a MS 5975C mass spectrometer. The Agilent DB-17 capillary column of dimensions of $60 \mathrm{~m} \times 0.25 \mathrm{~mm} \times 0.25 \mu \mathrm{m}$ was used. The obtained MS spectra were interpreted based on the reference MS library (chemical base G1034C). The contributions of the detected compounds were computed relatively as a ratio of peak area of particular compound to the summary peak area of all detected components.

The detailed information concerning the FT-IR, GPC and GC-MS analysis procedures and samples preparation were reported previously [16].

\section{Results and discussion}

\subsection{Effect of process variables on products yield}

The distribution of products of hydrothermal processing of pine wood as a function of processing temperature and time is shown in Fig. 2. Generally, it can be seen that the change of process temperature causes more pronounced changes in the yield distribution than reaction time. At $250{ }^{\circ} \mathrm{C}$, the dominant group fraction is solid residue, probably due to moderately-deep decomposition of original biomass matter. Consequently, longer processing time results in its gradual decrease from ca. 56 to ca. $47 \mathrm{wt} \%$, for 10 and 30 minutes, respectively. It is worth noting that at $250{ }^{\circ} \mathrm{C}$, a reaction time longer than 30 minutes does not lead to a further decrease of solid residue production. For the same conditions, the biooil yield varied in the range 20-26 wt.\%. In contrast to solids, increasing reaction time resulted in small changes in the yield of bio-oil and the gaseous fraction by few percentages. These observations might be the result of the gradual decomposition of original wood biomass towards molecules with lower mass. For instance, intensive decarboxylation may occur, as was confirmed by the gas analysis revealing the dominant contribution of carbon dioxide. These findings were similar to those reported elsewhere $[6,10]$. The yield of watersoluble organics was not found to be dependent on reaction time and equals approximately $11-13$ wt. $\%$ at the lower temperature. 
As mentioned above, the increase in the reaction temperature caused more pronounced changes in products distribution. At higher processing temperature, the bio-oil yield increased by a few points and varied within the range of ca. $33-38$ wt. $\%$. At $350{ }^{\circ} \mathrm{C}$ the highest yield (38.4 wt.\%) was recorded for the shortest processing time. The bio-oil yields found are in line (in the range of 35-45 wt.\%) with values previously reported for wood-type biomass $[11,13,17]$. A higher yield was obtained also for the gaseous phase, which varied between 11.4 to $14.3 \mathrm{wt} \%$ and only a slightly higher share was noted for water-soluble organics. These increased yields, in combination with the reduced solids yield, confirm that at $250{ }^{\circ} \mathrm{C}$ a significant fraction of the feed was still unconverted material. In case of a higher reaction temperature, the inverse effect of residence time change was noted in comparison with the runs at $250{ }^{\circ} \mathrm{C}$ for bio-oils and solids. Hence, the diminishing bio-oil formation can be explained by secondary reactions of unstable molecules composing bio-oils via repolymerization toward aromatics structure of solids (secondary biochar) or via cracking towards gaseous products. The lack of a diminishing yield of solids with prolongation of reaction time indicates that the majority of pine wood macromolecules underwent the decomposition at $350{ }^{\circ} \mathrm{C}$. The rest (approx. 28-30 wt.\%) can be formed by the most stable aromatic derivatives of lignin.

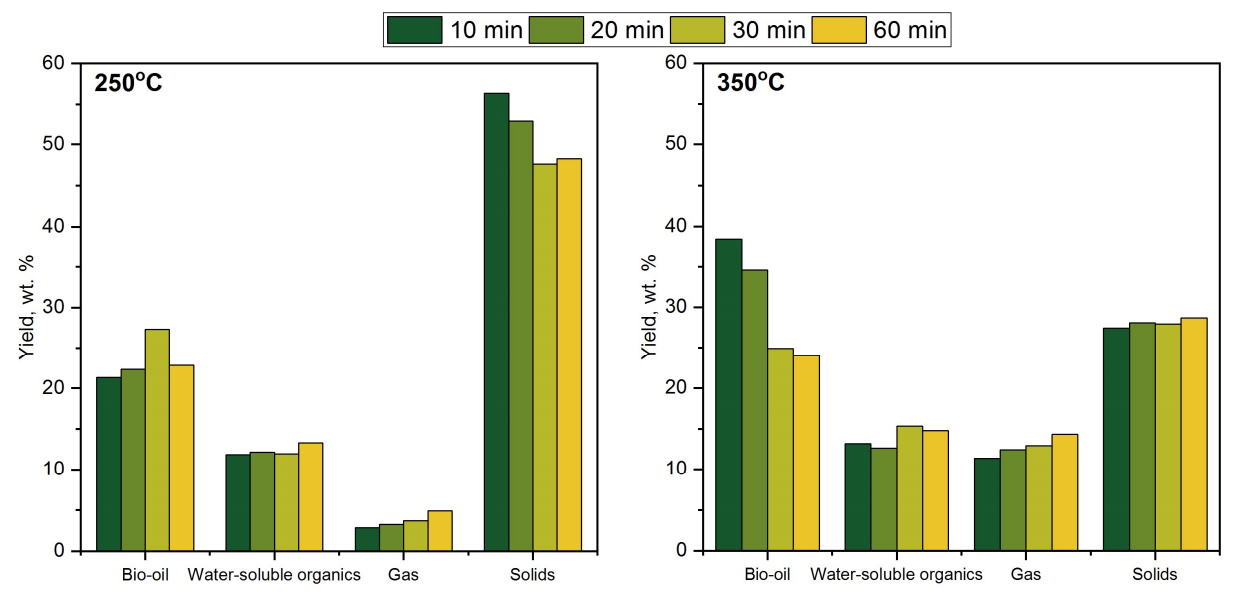

Fig. 2. Products yield distribution as a function of processing temperature and time.

\subsection{Effect of process variables on bio-oil composition}

\subsubsection{Elemental analysis}

The resultant bio-oils are highly viscous liquids with an intensive odor similar to pyrolysis bio-oils. In table 2 the results of the elemental compositions were collected. The carbon content in the bio-oils is higher than for the feedstock and varies between ca. 58-62 wt.\%. Additionally, the oxygen content in HTL liquid is much lower than in the original pine wood. The higher carbon and lower oxygen contents result in the increase of the higher heating value in comparison to the raw material. The highest HHV $\left(28.1 \mathrm{MJ} \cdot \mathrm{kg}^{-1}\right)$ was noted for biooil obtained at $350{ }^{\circ} \mathrm{C}$ for 60 minutes. Furthermore, the processing of pine wood at higher temperatures $\left(350^{\circ} \mathrm{C}\right)$ led to a higher carbon content and increase in the bio-oils HHV by few percentage compared to $250{ }^{\circ} \mathrm{C}$. The effect of residence time on elemental composition was irregular. For the sake of comparison of the effect of process conditions on bio-oils molar ratios change, a van Krevelen diagram was prepared (Fig. 3.). 
Table 2. Elemental composition and HHV of bio-oils obtained through HTL of pine wood under different processing conditions.

\begin{tabular}{|c|c|c|c|c|c|c|c|c|c|}
\hline & \multirow{2}{*}{ Wood } & \multicolumn{4}{|c|}{$250^{\circ} \mathrm{C}$} & \multicolumn{4}{|c|}{$350^{\circ} \mathrm{C}$} \\
\hline & & $10 \mathrm{~min}$ & $20 \mathrm{~min}$ & $30 \mathrm{~min}$ & $60 \mathrm{~min}$ & $10 \mathrm{~min}$ & $20 \mathrm{~min}$ & $30 \mathrm{~min}$ & $60 \mathrm{~min}$ \\
\hline C [wt.\%] & 46.58 & 60.0 & 58.9 & 58.3 & 62.5 & 63.4 & 63.3 & 65.7 & 66.2 \\
\hline H [wt.\%] & 6.34 & 6.2 & 6.5 & 6.0 & 6.3 & 6.3 & 6.3 & 6.4 & 6.7 \\
\hline N [wt.\%] & 0.04 & 0.6 & 0.5 & 0.0 & 0.5 & 0.5 & 0.4 & 0.4 & 0.1 \\
\hline O [wt.\%] & 46.98 & 33.3 & 34.1 & 35.6 & 30.7 & 29.8 & 30.0 & 27.6 & 27.0 \\
\hline $\begin{array}{c}\text { HHV } \\
{\left[\mathbf{M J} \cdot \mathbf{k g}^{-1}\right]}\end{array}$ & 18.57 & 24.6 & 24.5 & 23.6 & 26.0 & 26.3 & 26.3 & 27.5 & 28.1 \\
\hline
\end{tabular}

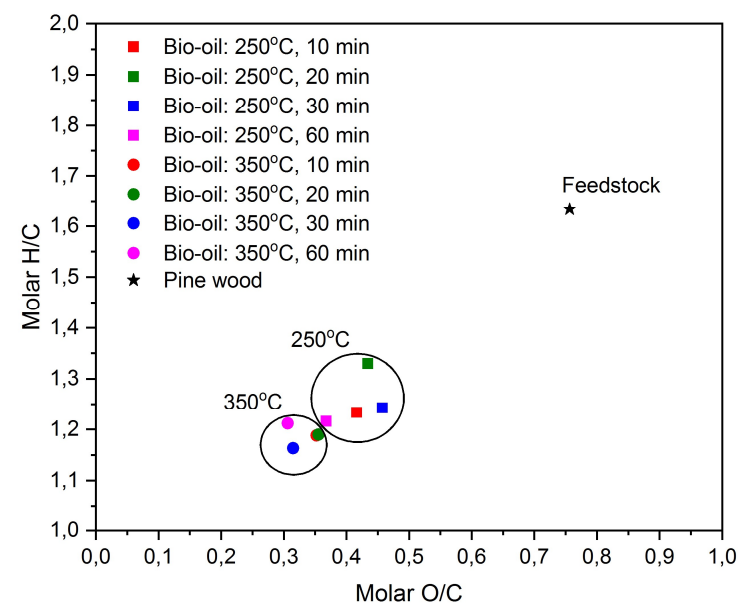

Fig. 3. Comprehensive van Krevelen diagram for the studied bio-oils and pristine feedstock.

Both the molar ratios of $\mathrm{O} / \mathrm{C}$ and $\mathrm{H} / \mathrm{C}$ of bio-oils are significantly lower compared to the feedstock, which suggests the occurence of intensive deoxygenation reaction via both dehydration or decarboxylation during hydrothermal liquefaction of pine wood. According to [18], the aforementioned reactions lead to the production of water-soluble organics and carbon dioxide as gaseous product. The reaction time didn't cause a systematic change of molecular ratios. However, at the lower temperature $\left(250^{\circ} \mathrm{C}\right)$ the fluctuations were more pronounced than at $350{ }^{\circ} \mathrm{C}$. It is clear that the increase in processing temperature by $100{ }^{\circ} \mathrm{C}$ led to the reduction of both molar ratios. The decrease in $\mathrm{H} / \mathrm{C}$ ratio could infer the increase of the fraction of aromatic compounds in bio-oil at the higher process temperature. To summarize, the reactions occurring during hydrothermal liquefaction caused significant energy densification compared to the raw material.

\subsubsection{Fourier-transform infrared spectroscopy}

The FT-IR analysis (cf. Fig. 4.) was carried out to assess the relative intensity changes of functional groups in the components of the bio-oils as a function of the process variables. The shape of absorption bands of collected spectra indicate the presence of aromatic hydrocarbons, phenols, as well as numerous oxygen-containing compounds (esters, ketones, aldehydes and alcohols). More specifically, the band at $3200-3600 \mathrm{~cm}^{-1}$ is typical for $-\mathrm{OH}$ stretching mode, which potentially could be assigned to phenols, carboxylic acids or alcohols. Also, the occurrence of those compounds group is evidenced by the presence of the bands in the spectral range of $950-1300 \mathrm{~cm}^{-1}$ which are ascribed to $\mathrm{C}-\mathrm{O}$ stretching and $-\mathrm{OH}$ bending 
vibrations. The absorptions between 3000 and $2800 \mathrm{~cm}^{-1}$ (C-H stretching vibrations) are attributed to $\mathrm{C}-\mathrm{H}$ stretching vibrations in aliphatic groups. Subsequently, the presence of peak centered at $1690 \mathrm{~cm}^{-1}$ refers to carbonyl groups $(\mathrm{C}=\mathrm{O}$ stretching) and suggests the presence of oxygen compounds like aldehydes, ketones and carboxylic acids. Finally, the presence of unsaturated bonds, e.g. aromatic rings is confirmed by the sharp characteristic stretching band of $\mathrm{C}=\mathrm{C}$ in the range 1670 and $1520 \mathrm{~cm}^{-1}$ and deformation vibrations at 700$900 \mathrm{~cm}^{-1}$.

The similarity in the discussed FT-IR spectra collected for all bio-oils clearly evidences their qualitative similarity. However, it is worth to mention that the effect of reaction time on quantitative composition of bio-oils depends on processing temperature. More specifically, the shape of the spectra of bio-oils produced at the lower temperature significantly differ depending on reaction time. In particular, for shorter processing period more intensive are the bands assigned to the presence of oxygen compounds, especially containing carbonyland hydroxyl groups. This groups seem to be less stable in case of longer processing time and break forming ultimately simplier compounds. Moreover, the prolongation of reaction time results in the intensification of the bands corresponding to $\mathrm{C}=\mathrm{C}$ aromatic compounds as well as the $\mathrm{C}-\mathrm{O}$ stretching vibrations. This could denote more intensive formation of phenols and its derivatives, which according to [19] could originate from the lignin or wood carbohydrates. Contrarily, the bio-oils obtained at $350{ }^{\circ} \mathrm{C}$ exhibit lack of noticeable dependence on processing time. Furthermore, the processing temperature exhibits impact for all tested processing times, but for the shorter reaction times (10-20 $\mathrm{min})$ the changes are more noticeable. In all cases, the increase in process temperature resulted in reduction of the intensity of carbonyl groups and $\mathrm{C}-\mathrm{O}$ bond. For the longest reaction times, the increase in process temperature caused increase in the intensity of hydroxyl groups and methyl and methylene groups, what could arise from the re-arrangement of phenol derivatives. The obtained results are in line with previous research $[14,18]$.
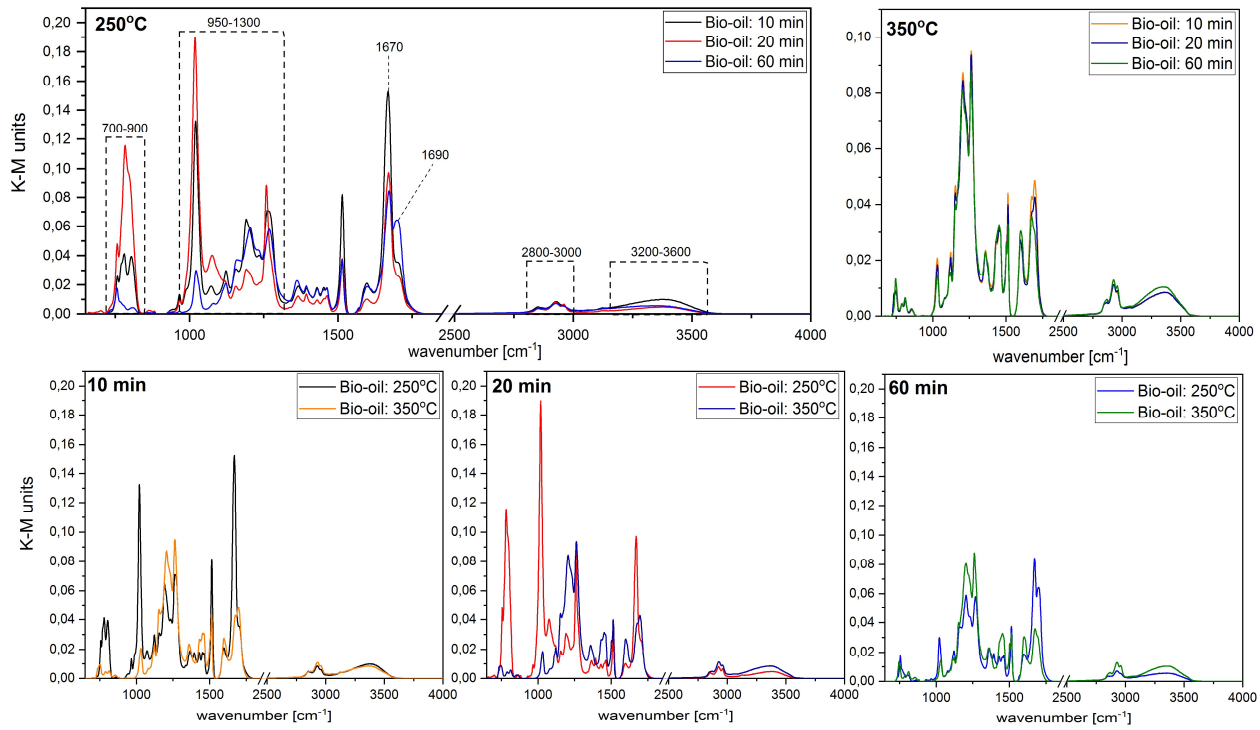

Fig. 4. ATR FT-IR spectra of bio-oils obtained by HTL of pine wood at $250{ }^{\circ} \mathrm{C}$ and $350{ }^{\circ} \mathrm{C}$ for 10,20 and $60 \mathrm{~min}$. 


\subsubsection{Gel permeation chromatography}

The impact of HTL processing temperature and time on molecular mass distribution of bio-oil components was investigated by means of GPC (Fig. 5.). The analyses revealed that all obtained bio-oils represent the mixtures of compounds with the wide molecular mass range between ca. $40 \mathrm{~g} \cdot \mathrm{mol}^{-1}$ and $3000 \mathrm{~g} \cdot \mathrm{mol}^{-1}$. For shorter reaction times, especially at lower temperatures, the samples exhibit one relatively sharp peak (centred at $120 \mathrm{~g} \cdot \mathrm{mol}^{-1}$ ) and few smaller ones (centred at 59, 173, $318 \mathrm{~g} \cdot \mathrm{mol}^{-1}$ ). Similiarly like for FT-IR analyses, the most significant differences were noticed for the lower processing temperature $\left(250^{\circ} \mathrm{C}\right)$. Prolongation of reaction time at $250{ }^{\circ} \mathrm{C}$ effects in a gradual reduction of intensity of the mentioned most pronounced peaks, and becoming the entire distribution curve more homogenous. The molecular weight distribution of the studied samples produced via HTL at $350{ }^{\circ} \mathrm{C}$ revealed the lack of significant dependence on reaction time. However, prolongation of reaction time at $350{ }^{\circ} \mathrm{C}$ caused a slight reduction of the heaviest compounds (especially in the range of 700-2000 $\left.\mathrm{g} \cdot \mathrm{mol}^{-1}\right)$ and increase in the lighter ones $\left(130-350 \mathrm{~g} \cdot \mathrm{mol}^{-}\right.$ $\left.{ }^{1}\right)$ due to gradual cracking and depolymerization reactions. This results are in compliance with information reported by [19]. Overall, it was estimated that from 41 to $57 \%$ (depending on process variables), of compounds present in bio-oil exhibit the molecular mass below 600 $\mathrm{g} \cdot \mathrm{mol}^{-1}$, being in the range of molecular mass of fuel oil distillates. Modification of processing temperature influenced also the shape of molecular distribution curve, while for the longest reaction time the difference was the least marked. On one hand, for each reaction time, the increase of processing temperature by $100{ }^{\circ} \mathrm{C}$ resulted in the diminish of the most intensive peaks. Those compounds, mostly with quite small molecular mass could undergo cracking and formulate the components of gas phase. On the other hand, this compounds could re-polymerize and formulate bio-oil components with higher molecular mass. It was evidenced by the increase in the amount of heavier compounds with processing temperature increment, especially for the longest processing time. Moreover, similar findings regarding re-polymerization under more severe conditions were also mentioned earlier [6].
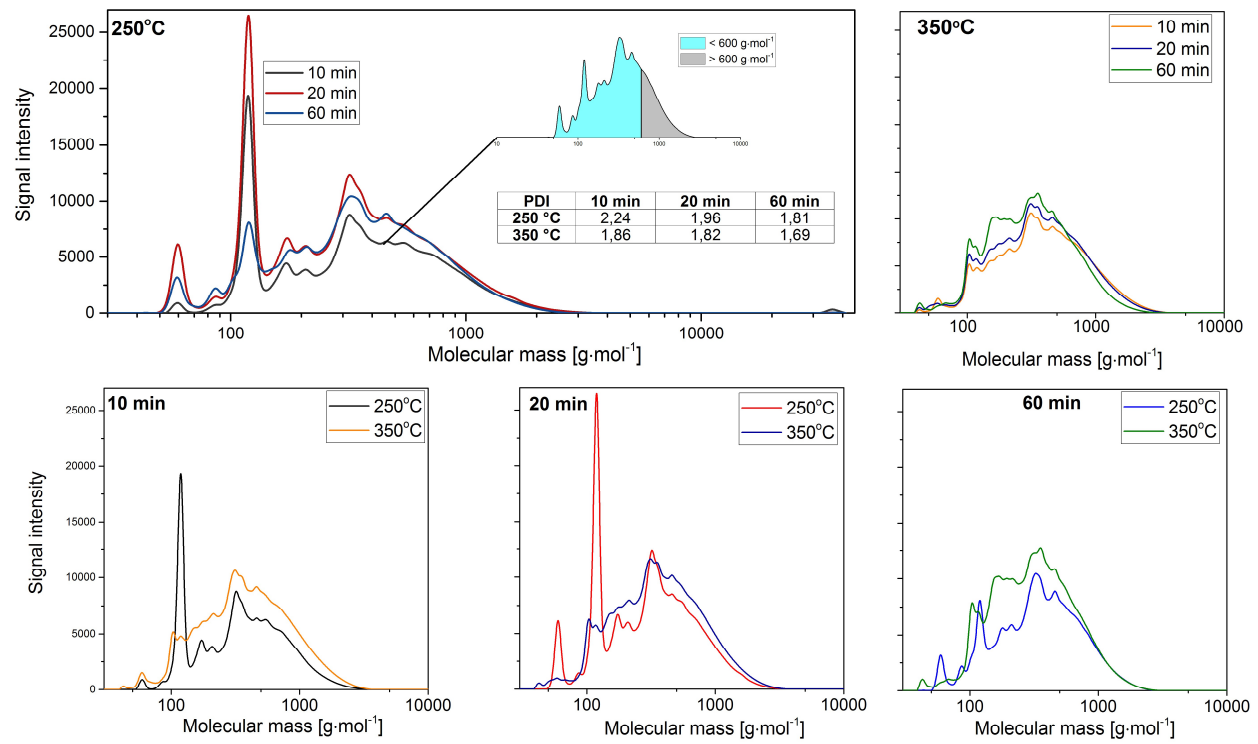

Fig. 5. Molecular mass distributions of pine wood HTL bio-oils obtained at different temperatures $\left(250\right.$ and $\left.350^{\circ} \mathrm{C}\right)$ and for different reaction times $(10,20$ and $60 \mathrm{~min})$, determined by GPC. 
For the studied pine wood HTL bio-oils, there is no characteristic tail, as reported for some GPC distribution curves of bio-oils obtained from different feedstocks [16]. This suggests the absence of highly stable macromolecular compounds in pine wood bio-oil, what is beneficial for its utilization as engine fuel. The resultant bio-oils are not highly heterogeneous, as evidenced by the relatively low polydispersity index (PDI) value varying in the range of 1.69-2.24. The highest value of PDI was found for the bio-oil obtained at $250{ }^{\circ} \mathrm{C}$ for $10 \mathrm{~min}$. The increase in processing time and temperature lead to reduction of PDI index due to occurring secondary reactions (cracking and depolymerization of intermediates of hydrolysis process) and production of stable compounds.

\subsubsection{Gas chromatography coupled to mass spectrometry}

The qualitative analysis of light fractions of the bio-oils (i.e. these with a boiling temperature up to approx. $300^{\circ} \mathrm{C}$ ) was carried out by means of a gas chromatography coupled to mass spectrometry (GC-MS). Considering only the peaks of the sufficiently high match factor $(80 \%)$ with electronic library search routines, we gathered comparatively the list of the relative shares of chosen compounds as a function of process variables, as presented in Table 3. The main types of compounds identified in bio-oil are phenol and its derivatives, heterocyclic oxygen compounds (ketones, aldehydes), aliphatic ketones and esters, as well as aromatics.

Table 3. The relative contributions of the selected compounds identified in HTL bio-oil obtained at different temperatures and residence times.

\begin{tabular}{|c|c|c|c|c|c|c|}
\hline \multirow{3}{*}{$\begin{array}{c}\text { RT } \\
{[\text { min] }}\end{array}$} & \multirow{3}{*}{ Compound name } & \multicolumn{5}{|c|}{ Relative share [area \%] } \\
\hline & & \multicolumn{4}{|c|}{$350{ }^{\circ} \mathrm{C}$} & $250{ }^{\circ} \mathrm{C}$ \\
\hline & & $10 \mathrm{~min}$ & $20 \mathrm{~min}$ & $30 \mathrm{~min}$ & \multicolumn{2}{|c|}{$60 \mathrm{~min}$} \\
\hline 9.3 & toluene & - & 8.2 & - & - & - \\
\hline 16.3 & 2-cyclopenten-1-one & 6.8 & 4.2 & 3.4 & 2.2 & 23.6 \\
\hline 19.1 & 2-methyl-2-cyclopenten-1-one & 4.0 & 5.1 & 5.8 & 5.1 & - \\
\hline 22.5 & 2,5-hexanedione & - & 5.4 & - & 3.5 & - \\
\hline 23.4 & 5-methylfurfural & - & - & - & - & 5.8 \\
\hline 24.1 & 3-methyl-2-cyclopenten-1-one & - & - & 4.6 & - & - \\
\hline 26.7 & 2,3-dimethyl-2-cyclopenten-1-one & - & - & 3.9 & 6.5 & - \\
\hline 26.9 & $\begin{array}{l}\text { 2-hydroxy-3-methyl-2-cyclopenten- } \\
\text { 1-one }\end{array}$ & - & - & - & - & 10.2 \\
\hline 28.7 & phenol & - & - & 2.3 & 2.5 & - \\
\hline 29.4 & guaiacol & 23.5 & 28.8 & 32.1 & 29.8 & 11.4 \\
\hline 34.2 & 4-methyl guaiacol & 9.7 & 14.1 & 14.8 & 15.1 & - \\
\hline 38.0 & 4-ethyl guaiacol & 6.1 & 8.2 & 8.8 & 9.6 & - \\
\hline 41.6 & 2-methoxy-4-propylphenol & - & - & - & 3.4 & - \\
\hline 46.9 & vanillin & 3.8 & - & - & - & 12.0 \\
\hline 74.6 & $\begin{array}{c}\text { bis (2-ethylhexyl ) ester } \\
\text { hexanedioic acid }\end{array}$ & 29.2 & - & - & - & - \\
\hline 78.5 & $\begin{array}{c}\text { 2,2'-methylenebis[6-(1,1- } \\
\text { dimethylethyl)-4-ethylphenol }\end{array}$ & 4.0 & 7.4 & 6.9 & 7.8 & 13.6 \\
\hline
\end{tabular}

The presence of furfural derivatives and cyclic ketones indicate the hemicellulose and cellulose decomposition. Under hydrothermal conditions polysaccharides like hemicellulose 
or cellulose are depolymerized to smaller monosaccharides and the formed hexoses and pentoses tend to recombine to cyclic structures. Those compounds might be further decomposed to e.g. acetic acid or formic acid [20]. However, the adjustment of process variables into more harsher, results in gradual decrease in relative concentration of those structures. For instance, the relative amount of cyclopenten-1-one changed from $23.6 \%$ to $2.2 \%$, when the process temperature was increased by $100{ }^{\circ} \mathrm{C}$. Probably those compounds could undergo re-arrangements and form more complex structures. Similarly, another compound detected in milder conditions was vanillin, which according to Ruiz [21] suggests the decomposition of lignin from the guaiacyl unit of lignin. The concentration of vanillin is much higher for experiments at the lower temperatures and longer reaction time $\left(250{ }^{\circ} \mathrm{C}\right.$ and $60 \mathrm{~min}$ ). The main compound type of the bio-oil produced at $350{ }^{\circ} \mathrm{C}$ is guaiacol and its derivatives, which were found in all runs, and for which the total contribution increase with prolongation of time processing. Guaiacol is formed from lignin through hydrolysis and dealkylation. Other compounds from the lignin decomposition detected by GC-MS are 4methylguaiacol, 4-ethylguaiacol, and vanillin. Longer reaction time leads to the partial decomposition of guaiacol resulting in the formation of phenol in bio-oil after 30 minutes run. For the longer reaction time, more of phenol derivatives occur which can mean that higher temperatures and over longer reaction time the lignin is deeper decomposed. Lignin is a dominant origin of phenol, but according to [20] phenol can be also produced from cellulose.

\section{Conclusion}

The HTL pine wood bio-oils were dark and viscous liquids with an appearance similar to crude petroleum or heavy tar. The maximum bio-oil yield (38.35 wt.\%) was obtained at $350{ }^{\circ} \mathrm{C}$ for $10 \mathrm{~min}$., implying an energy recovery in the form of bio-oil of $54 \%$. The increase in process temperature resulted in a slight rise of carbon content in the resultant oil, while the hydrogen and nitrogen contents remained at an approximately the same level. Interestingly, the hydrothermal liquefaction of this biomass at temperatures closer to critical point of water caused a considerable drop in the oxygen content. The HHV of the bio-oils were significantly higher compared to the original biomass, what makes the resultant bio-oils attractive in view of use as bio-fuel components. It should be also emphasized that bio-oils obtained from pine wood through hydrothermal liquefaction contain high content of phenol derivatives as well as numerous other oxygenates like esters, acids and ketones. The variety of compounds present in bio-oil originates from the original macromolecules like cellulose, hemicellulose and lignin that underwent a series of complex reactions, i.e. depolymerization, rearrangement and secondary reactions of the intermediates. Despite the high heterogeneity of the composition of the bio-oil, the product is a promising, valuable intermediate that may act as a source of many value-added chemicals that could find their applications in various branches of industry. Additionally, by adjustment of the process conditions results even higher yields and steering of the quality of the resulting bio-oil product is anticipated.

This paper was prepared under support of the project number 15.11.210.451. The research was carried out using the infrastructure of the AGH Centre of Energy, AGH University of Science and Technology.

\section{References}

1. Eurostat, Wood as a source of energy (2017) doi: 10.2785/570022

2. Guo, M., Song, W., Buhain, J., Renew. Sustain. Energy Rev. 42, 712 (2015)

3. Cao, L., Zhang, C., Chen, H., Tsang, D.C.W., Luo, G., Zhang, S., Chen, J., Bioresour. Technol. 245, 1184 (2017) 
4. Kan, T., Strezov, V., Evans, T.J., Renew. Sustain. Energy Rev. 57, 126 (2016)

5. Tekin, K., Karagöz, S., Bektaş, S., Renew. Sustain. Energy Rev. 40, 673 (2014)

6. Wądrzyk, M., Janus, R., Jakóbiec, J., Przem. Chem. 96, 1913 (2017)

7. Peterson, A.A., Vogel, F., Lachance, R.P., Fröling, M., Antal, M.J., Tester, J.W., Energy Environ. Sci. 1, 32 (2008)

8. Toor, S.S., Rosendahl, L., Rudolf, A., Energy. 36, 2328 (2011)

9. Dimitriadis, A., Bezergianni, S., Renew. Sustain. Energy Rev. 68, 113 (2017)

10. Gollakota, A.R.K., Kishore, N., Gu, S., Renew. Sustain. Energy Rev. 81, 1378 (2018)

11. Brilman, D.W.F., Drabik, N., Wądrzyk, M., Biomass Convers. Biorefinery 7, 445 (2017)

12. Liu, Z., Zhang, F., Energy Convers. Manag. 49, 3498 (2008)

13. Doassans-Carrère, N., Ferrasse, J.-H., Boutin, O., Mauviel, G., Léde, J., Universite, A.M., Marseille, C., Umr, M.P., Energy Fuels. 28, 5103 (2014)

14. Ã, Y.Q., Zuo, C., Tan, J., He, J., Energy. 32, 196 (2007)

15. Westerhof, R.J.M., Brilman, D.W.F., Garcia-perez, M., Wang, Z., Oudenhoven, S.R.G., Swaaij, W.P.M. Van, Kersten, S.R.A., Energy Fuels. 25, 1817 (2011)

16. Wądrzyk, M., Janus, R., Vos, M.P., Brilman, D.W.F., J. Anal. Appl. Pyrolysis. 134, 415 (2018)

17. Sun, P., Heng, M., Sun, S., Chen, J., Energy Convers. Manag. 52, 924 (2011)

18. Nazari, L., Yuan, Z., Souzanchi, S., Ray, M.B., Xu, C.C., Fuel 162, 74 (2015)

19. Kumar, S., Lange, J., Rossum, G. Van, Kersten, S.R.A., Ind. Eng. Chem. Res. 53, 11668 (2014)

20. Tekin, K., Karagoz, S., Res Chem Intermed, 39, 485 (2013)

21. Ruiz, A., Rodriguez, R.M., Fernandes, B.D., Vicente, A.A., Teixeira, J.A., Renew. Sustain. Energy Rev. 21, 35 (2013) 